\title{
Propriedades químicas de Latossolo Vermelho em função da aplicação de gessagem e calagem
}

\author{
Chemical properties of Ultisol due to the \\ application of limestone and gypsum \\ Leandro Colares Vilela ${ }^{[\mathrm{a}]}$, Antonio Clementino dos Santos ${ }^{[\mathrm{b}]}$, \\ Paulo Matos Barreto ${ }^{[\mathrm{c}]}$, Suelen dos Santos Brito ${ }^{[\mathrm{d}]}$, \\ José Expedito Cavalcante da Silva ${ }^{[\mathrm{e}]}$, Leonardo Bernardes Taverny de Oliveira ${ }^{[\mathrm{f}]}$

\footnotetext{
[a] Zootecnista, Universidade Federal do Tocantins (UFT), Araguaina, TO - Brasil, e-mail: leandrocolares@hotmail.com

${ }^{[b]}$ Engenheiro agrônomo, Doutor em Tecnologias Energéticas Nucleares pela Universidade Federal de Pernambuco (UFPE), professor adjunto III da Universidade Federal do Tocantins (UFT), Araguaina, TO - Brasil, e-mail: clementino@uft.edu.br

[c] Químico,Mestrandoem CiêncianaUniversidadeFederaldoTocantins (UFT),Araguaina,TO-Brasil, e-mail:paulobarreto13@hotmail.com

[d] Zootecnista Graduada pela Universidade Federal do Tocantins (UFT), Mestranda em Ciência Animal Tropical pela Universidade Federal do Tocantins (UFT), Araguaina, TO - Brasil, e-mail: suelenbritovip@hotmail.com

[e] Doutor em Química pela Universidade Federal de Pernambuco (UFPE), professor adjunto e vice-reitor da Universidade Federal do Tocantins (UFT), bolsista produtividade do CNPq, Araguaina, TO - Brasil, e-mail: jecs@uft.edu.br

[f] Zootecnista, Universidade Federal do Tocantins (UFT), Araguaina, TO - Brasil, e-mail: tavernydeoliveira@hotmail.com
}

\section{Resumo}

A utilização de corretivo (calcário) e aditivo (gesso) é a prática adotada para o suprimento da Ca+2 e $\mathrm{Mg}+2$ e a disponibilidade de nutrientes. Em experimento desenvolvido em casa de vegetação estudouse o efeito da aplicação de doses de corretivo e aditivo $(0 \%, 50 \%, 100 \%, 200 \%$ e $400 \%$ da dose de calcário e gesso), durante quatro períodos de coleta (30, 60, 90 e 120 dias após aplicação), em Latossolo Vermelho distrófico do Estado do Tocantins. O objetivo do trabalho foi avaliar o efeito da correção da acidez (calcário) e de aditivo de solo (gesso) por meio das características químicas, em solo coletado (0$20 \mathrm{~cm}$ ) na região de transição Cerrado/Floresta Amazônica. Nas amostras coletadas foram analisadas as propriedades químicas do solo (valor V, valor T, relação Ca: $\mathrm{Mg}, \mathrm{pH}, \mathrm{Al}+3$ e $\mathrm{H}+$ ) aos 30, 60, 90 e 120 dias após a aplicação do calcário e do gesso. As análises periódicas do solo indicaram que a gessagem e a calagem influenciaram as características químicas do solo (valor $\mathrm{V}$, valor T, relação Ca: $\mathrm{Mg}, \mathrm{Al}+3 \mathrm{e} \mathrm{H}+$ ). A resposta do calcário está diretamente ligada ao tempo após a aplicação no solo.

Palavras-chave: $\mathrm{CaCO}_{3}$. Disponibilidade de nutrientes. Fertilidade do solo. 


\begin{abstract}
The use of lime (limestone) and additive (gypsum) is the practice adopted for the supply of $\mathrm{Ca}+2$ and $\mathrm{Mg}+2$ and the availability of nutrients. Experiments were carried out in a greenhouse where the effect of doses of corrective and additive (0\%,50\%,100\%,200\% and 400\% of lime and gypsum) was studied during four sampling periods (30,60, 90 and 120 days after application) in a soil of Tocantins State. The objective was to evaluate the effect of the soil acidity correction (lime) and with additive (gypsum), through the chemical characteristics of the collected soil $(0-20 \mathrm{~cm})$ in the transition area of savanna/Amazon forest. In the collected samples, soil chemical properties were analyzed ( $V$ value, T value, $\mathrm{Ca}: \mathrm{Mg}, \mathrm{pH}, \mathrm{Al+3}$ and $\mathrm{H}+1$ ) 30, 60, 90 and 120 days after the application of lime and gypsum. The periodic analysis of soil indicated that the gypsum and liming influenced the soil chemical characteristics ( $V$ value, T value, Ca: $M g, A l+3$ and $H+1)$. The response of limestone is directly linked to the time after soil application.
\end{abstract}

Keywords: $\mathrm{CaCO}_{3}$. Nutrients availability. Soil fertility.

\title{
Introdução
}

No Cerrado e na Amazônia, os solos em sua maioria são ácidos, constituindo condição adversa para a maioria das culturas. As limitações de uso, todavia, vão além da camada arável, atingindo as camadas subsuperficiais, nas quais a toxidez do alumínio $\left(\mathrm{Al}^{+3}\right)$ e a baixa disponibilidade de cálcio $\left(\mathrm{Ca}^{+2}\right)$ e magnésio $\left(\mathrm{Mg}^{+2}\right)$ são os principais fatores que impedem a maximização das produções, por limitar o desenvolvimento radicular e, consequentemente, a utilização de água e de nutrientes em profundidade. Dessa forma, práticas

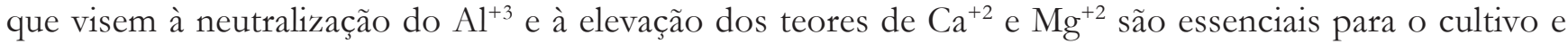
produção (SILVA et al., 1998).

A calagem é uma das práticas de manejo que mais aumentam o potencial produtivo das culturas nas regiões tropicais e subtropicais, em função da neutralização da acidez e disponibilidade de cálcio e magnésio. A elevação do pH do solo aumenta a disponibilidade de fósforo (P) (ERNANI et al., 1996), favorece a atividade microbiana e diminui ou elimina a fitotoxidez do Al e do Mn (ERNANI et al., 1998), com reflexos positivos na absorção de água e de nutrientes.

A toxidez causada pelo $\mathrm{Al}$ é um dos mais importantes fatores que limitam o crescimento das plantas em solos ácidos, principalmente em $\mathrm{pH}$ abaixo de 5,0. $\mathrm{O} \mathrm{Al}^{+3}$ acumula-se, preferencialmente, no sistema radicular das plantas, sendo pequena a quantidade translocada para a parte aérea (MASSOT et al., 1992).

A calagem afeta a eletroquímica de solos tropicais de carga variável. O aumento do potencial elétrico superficial contribui para a dispersão de argila, principalmente de microagregados. Entretanto, a influência da calagem na dispersão de argila, bem como na estabilidade de macroagregados, deve ser dependente do seu efeito no aumento da quantidade de resíduos vegetais adicionados ao solo, os quais são fontes de $\mathrm{C}$ e energia aos microrganismos e, portanto, podem determinar aumento da atividade microbiana no solo (CHAN; HEENAN, 1999).

Resultados de pesquisas realizados em solos brasileiros indicaram pequenos ou nenhum movimento do calcário em períodos curtos, além do local de sua aplicação (GONZÁLES-ERICO et al., 1979; RITCHEY et al., 1980; PAVAN et al., 1984). Outros trabalhos realizados no Brasil (CHAVES et al., 1984) e em regiões subtropicais úmidas (MOSCHLER et al., 1973; BLEVINS et al., 1978) observaram aumentos de $\mathrm{pH}$ e $\mathrm{Ca}^{+2}$ trocável e redução de $\mathrm{Al}^{+3}$ trocável no solo com a aplicação de calcário na superfície.

A lixiviação de bases, provocada pelo uso do gesso, estabelece, nas camadas subsuperficiais, expressiva diferença entre esse produto e o calcário, em termos de correção de acidez e de disponibilidade de $\mathrm{Mg}^{+2}$ e Ca ${ }^{+2}$ (SILVA et al., 1997). Os mecanismos propostos incluem o deslocamento do $\mathrm{Al}^{+3}$ pelo $\mathrm{Ca}^{+2}$ e, consequentemente, lixiviação do alumínio solúvel. Segundo Oates e Caldwell (1985), a forma $\mathrm{AlSO}_{4}{ }^{+}$é 
de lixiviação mais fácil do que as demais formas de $\mathrm{Al}^{+3}$. Outro mecanismo seria a redução da atividade do $\mathrm{Al}^{+3}$ pela formação de pares iônicos com o íon sulfato e aumento da concentração de $\mathrm{Ca}^{+2}$ (SUMMER et al., 1986).

O gesso que atua no fornecimento de $\mathrm{S}$ também supre o $\mathrm{Ca}^{+2}$ ao sistema solo-planta, elevando as concentrações desse elemento na massa seca das forrageiras. Isso provavelmente é decorrente do aprofundamento do sistema radicular, permitindo maior absorção de $\mathrm{Ca}^{+2}$ e $\mathrm{S}$ nas camadas mais profundas (QUAGGIO et al., 1993). O efeito benéfico do gesso, promovendo o aprofundamento do sistema radicular, foi demonstrado pela primeira vez no País em experimento com milho desenvolvido em Latossolo Vermelho-Escuro argiloso do Brasil central, relatado por Ritchey et al. (1980).

Segundo Corsi e Nussio (1992), os trabalhos para recuperação da fertilidade do solo devem ser iniciados elevando a saturação de base do solo para 70\%, com o objetivo de elevar o pH acima de 5,5, quando $\mathrm{o} \mathrm{Al}^{+3}$ precipita. Acima desse nível de $\mathrm{pH}$ tem início a decomposição e a mineralização da matéria orgânica (M.O.) do solo. Dessa forma, a M.O. passa a contribuir com o aumento capacidade de troca catiônica (T).

A recomendação de calagem e gessagem não é procedimento simples, por pressupor o conhecimento de número razoável de informações adicionais, como: características da propriedade agrícola (caracterização da área, da cultura, tipo de solo, histórico da área, expectativa de rendimento, etc.), conhecimento tecnológico (tem sua origem na pesquisa naquela região ou Estado) e, por último, informações oriundas das condições do mercado, principalmente aquelas relacionadas a preços de insumos e também disponibilidade de crédito, que são independentes das duas anteriores. Com base no exposto, o presente trabalho objetivou avaliar o efeito da correção (calcário) da acidez e de aditivo de solo (gesso) por meio das características químicas do solo coletado $(0-20 \mathrm{~cm})$ na região de transição Cerrado/ Floresta Amazônica.

\section{Material e métodos}

O experimento foi conduzido na casa de vegetação do Laboratório de Solos da Escola de Medicina Veterinária e Zootecnia da Universidade Federal de Tocantins, câmpus de Araguaína, TO. Amostras de Latossolo Vermelho (15 anos de cultivo intensivo com pastagens) foram coletadas na profundidade de 0-20 cm e levadas ao laboratório, e uma subamostra foi retirada e preparada (terra fina seca ao ar - TFSA), com a finalidade de quantificar os teores de $\mathrm{K}^{+}, \mathrm{Ca}^{+2} \mathrm{e} \mathrm{Mg}^{+2}, \mathrm{H}^{+}, \mathrm{Al}^{+3}$, $\mathrm{T}$ e $\mathrm{V}$ aportados pelo solo, cuja caracterização foi: $\mathrm{pH}\left(\mathrm{CaCl}_{2}\right)-3,8$; $\mathrm{P}: 1,5 \mathrm{mg} \mathrm{dm}{ }^{-3} ; \mathrm{K}^{+}: 2,0 \mathrm{mmol} \mathrm{dm}{ }^{-3} ; \mathrm{Ca}^{+2}: 1,4 \mathrm{mmol} \mathrm{dm}{ }^{-3} ; \mathrm{Mg}^{+2}: 0,6 \mathrm{mmol} \mathrm{dm}^{-3} ; \mathrm{Al}^{+3}$ : $2,2 \mathrm{mmol} \mathrm{dm}^{-3} ; \mathrm{H}^{+}+\mathrm{Al}^{+3}: 8,8 \mathrm{mmol} \mathrm{dm}^{-3}$. As análises dos teores de $\mathrm{P}$ e $\mathrm{K}$ extraíveis com Mehlich-1 foram quantificadas por colorimetria e fotometria de chama, respectivamente. $\mathrm{O} \mathrm{Ca}^{+2}$ e o $\mathrm{Mg}^{+2}$ trocáveis foram extraídos com KCl1 mol L-1 e os demais elementos $\left(\mathrm{Al}^{+3} \mathrm{e} \mathrm{H}^{+}\right)$determinados por titulação (EMBRAPA, 1997).

Antes da implantação do experimento foi realizada análise química do solo, com a finalidade de encontrar as doses adequadas dos corretivos para serem ali empregados. A dose de calcário utilizado (calcário dolomítico) visou à saturação por base de $70 \%$, até $20 \mathrm{~cm}$ de profundidade de solo, e foi calculada de acordo com a área da coluna. Já a dose de gesso foi calculada em função da fórmula: NG (necessidade de gesso em kg $\left.\mathrm{ha}^{-1}\right)=75 \mathrm{x} \%$ de argila, também calculada em função da área da coluna de solo. Em seguida, os solos foram colocados nos recipientes irrigados até chegarem às condições de capacidade de campo, pesados e colocados os corretivos nas doses pré-estabelecidas, conforme Embrapa (1997).

O delineamento experimental utilizado foi inteiramente casualizado, em arranjo fatorial $2 \times 5 \times 4$, com quatro repetições, sendo um corretivo (calcário) e um aditivo (gesso), cinco doses de calagem [método da saturação por base - NC: T (V2 - V1)/100] e gessagem - [NG: 75 x \% de argila], sendo (0\%, 50\%, 100\%, 200 e 400\% da dose recomendada), e quatro período de coleta (30, 60, 90 e 120 dias após aplicação), totalizando 160 unidades experimentais.

Em seguida, o solo foi colocado nos recipientes e irrigado até chegar às condições de capacidade de campo (CC) - considerando-se a CC a água retida a $0,03 \mathrm{MPa}$ - e mantido nessa condição até o fim do experimento, por meio de pesagens diárias. 
Após 30 dias da implantação do experimento foi realizada a primeira coleta de dados e analisada as propriedades químicas do solo, conforme metodologia da Embrapa (1997). Posteriormente aos 60, 90 e 120 dias foram realizados os mesmos procedimentos. Vale salientar que os vasos eram mantidos apenas com o solo, eliminando toda e qualquer plântula que germinasse no período de condução do experimento.

Após a obtenção de todos os dados, a análise de variância (ANOVA) foi realizada, utilizandose esquema fatorial $2 \times 5 \times 4$, com quatro repetições (dois corretivos, três profundidades analisadas e três períodos de coletas) (SAS, 1998). As médias foram comparadas aplicando-se o teste de Tukey, a 5\% de probabilidade.

\section{Resultados e discussão}

A aplicação de doses de calcário e gesso proporcionaram aumentos significativos $(\mathrm{p}<0,05)$ na saturação por base - V (Figura 1a), na capacidade de troca catiônica - T (Figura 1b), na relação Ca/ $\mathrm{Mg}$ (Figura 1d) e na diminuição dos teores de $\mathrm{Al}^{+3}$ (Figura 1f) no Latossolo Vermelho. Com relação ao $\mathrm{pH}$ (Figura 1c), verifica-se que apenas o calcário contribuiu positivamente $(\mathrm{p}<0,05)$, concordando com Caíres et al. (2003), em que o calcário incorporado aumentou o pH do solo. Sabe-se que o gesso é apenas um condicionador, que, conforme a Figura 1f, contribuiu para a diminuição do $\mathrm{Al}^{+3}$ no solo. A aplicação de gesso na superfície seguida por lixiviação para subsolos ácidos (SUMMER et al., 1986; CARVALHO; RAIJ, 1997) resulta no aumento da concentração de $\mathrm{Ca}^{+2}$, na formação de espécies menos tóxicas de $\mathrm{Al}^{+3}$ $\left(\mathrm{AlSO}_{4}^{+}\right.$) e na precipitação de $\mathrm{Al}^{+3}$ (HAINBERG et al., 1989). O gesso agrícola mostra-se mais efetivo na redução da toxidez de $\mathrm{Al}^{+3}$ do que o sulfato de cálcio puro, por causa da presença de $\mathrm{F}^{-}$, um ânion que forma complexos mais estáveis com $\mathrm{Al}^{+3}$ do que o $\mathrm{SO}_{4}^{2-}$ (CAMERON et al., 1986).

Oliveira e Pavan (1996) verificaram que o tempo ocorrido para a máxima reação do calcário aplicado na superfície foi de 32 meses, em Latossolo Vermelho argiloso, e de 28 a 30 meses, em Latossolo Vermelho textura média. De acordo com Caíres et al. (2000), o calcário incorporado aumentou o pH do solo de forma semelhante à calagem superficial, em dose única, na camada de 0-5 cm; apresentou, porém, reação significativamente maior nas profundidades de $5-10 \mathrm{~cm}$ e $10-20 \mathrm{~cm}$. Mesmo com a incorporação, a maior reação do calcário nas camadas superficiais do solo ocorreu entre 23 e 35 meses após a aplicação. Esse tempo de reação foi semelhante ao obtido por Oliveira et al. (1997) com o calcário incorporado na camada arável, em sistema convencional de preparo do solo. É interessante notar que o calcário, quando incorporado, proporcionou aumento significativo do pH no subsolo (20-40 cm e 40-60 cm) após 11 meses, que permaneceu consistente até 35 meses depois de sua aplicação.

Com relação ao valor $\mathrm{V}$ (Figura 1a), valor $\mathrm{T}$ (Figura 1b), pH (Figura 1c) e relação Ca/Mg (Figura 1d) em função da dose de gesso e calcário recomendada, observa-se que o gesso e o calcário influenciaram positivamente $(\mathrm{p}<0,01)$ nesses atributos, contribuindo para o aumento deles, sendo que a gessagem não influenciou no $\mathrm{pH}$ e na relação $\mathrm{Ca} / \mathrm{Mg}$ (Figuras 1c e 1d). Esses resultados foram obtidos em função do gesso apresentar alta solubilidade, movimentando-se ao longo do perfil sob influência do excesso de umidade (SUMMER, 1986). Por ser subproduto da indústria de fertilizantes fosfatados, o gesso agrícola é comercializado a baixo custo, e por isso é mais acessível. Após a aplicação de gesso agrícola $\left(\mathrm{CaSO}_{4} \cdot 2 \mathrm{H}_{2} \mathrm{O}\right)$, não se espera a elevação do pH, mas ocorre a diminuição do teor de alumínio tóxico, que pode eliminar também a toxidez de sódio, além de ser fonte de dois macronutrientes secundários: cálcio e enxofre. Ainda se observa que o gesso contribuiu para a diminuição dos teores de $\mathrm{Al}^{+3}$ nas camadas subsuperficiais.

Com relação ao $\mathrm{H}^{+}$e $\mathrm{Al}^{+3}$ (Figuras 1e e 1f), em função da dose de gessagem e calagem recomendadas, observa-se que contribuíram para a diminuição desses elementos no solo ( $\mathrm{p}<0,01)$. Os íons $\mathrm{H}^{+}$dissociados na fase líquida são denominados de acidez ativa, que é estimada pelo pH. Os demais íons $\mathrm{H}^{+}$e $\mathrm{Al}^{+3}$, ligados à fase sólida, são denominados acidez potencial. Apenas parte dos íons alumínio é deslocada por outros cátions, sendo por isso denominada de $\mathrm{Al}^{+3}$ trocável ou acidez trocável.

Rev. Acad., Ciênc. Agrár. Ambient., Curitiba, v. 8, n. 1, p. 19-27, jan./mar. 2010 


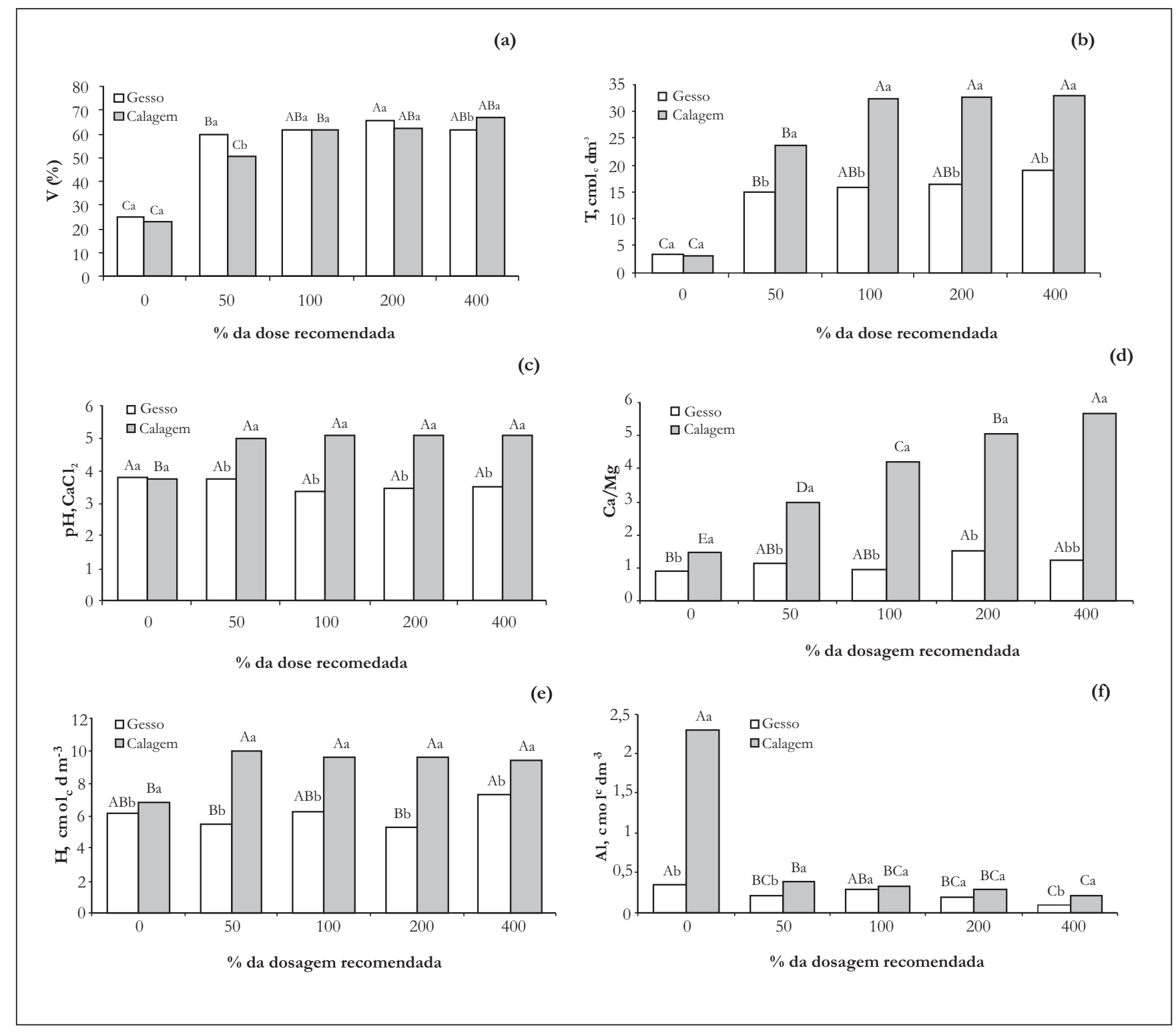

Figura 1 - Efeito das doses de gessagem e calagem sobre a saturação de base -V (a), capacidade de troca catiônica - T (b), $\mathrm{pH}(\mathrm{c})$, relação $\mathrm{Ca} / \mathrm{Mg}(\mathrm{d})$, hidrogênio - $\mathrm{H}^{+}(\mathrm{e})$, e Alumínio - $\mathrm{Al}^{+++}(\mathrm{f})$

Nota: Letras maiúsculas diferentes indicam diferença $(\mathrm{p}<0,05)$ entre doses de calcário e gessagem e letras minúsculas diferentes indicam diferença $(\mathrm{p}<0,05)$ entre o corretivo (calcário) e o aditivo (gesso) na mesma dose.

O efeito do alumínio trocável $\left(\mathrm{Al}^{+3}\right)$ em níveis tóxicos sobre o desenvolvimento radicular se caracteriza pela inibição do alongamento da raiz principal e pelo engrossamento das pontas das raízes, resultando em exploração de menor volume de solo pelas plantas, redução na absorção de nutrientes e no aproveitamento da água do solo (GOMES, 2002).

$\mathrm{Na}$ Figura 2 observa-se a influência do período de incubação da gessagem e calagem recomendadas sobre a saturação de base - V, capacidade de troca catiônica - T, pH, relação Ca: $\mathrm{Mg}$, hidrogênio - $\mathrm{H}^{+}$, e Alumínio $-\mathrm{Al}^{+3}$. Verifica-se que, para as variáveis analisadas, a influência do período de incubação foi mais acentuada $(p<0,05)$ na utilização da calagem em relação à gessagem. A necessidade de correção não está somente relacionada com o pH do solo, mas também com seu poder tampão hidrogeniônico, relacionando-se diretamente com os teores de argila e de matéria orgânica e com o tipo de argila. 
Quando se compara dentro das doses os períodos de incubação (Figura 3) para os elementos analisados, observa-se que para tais variáveis a incubação influenciou os elementos no solo $(\mathrm{p}<0,05)$. O conhecimento da melhor dose de corretivo e aditivo é, portanto, fundamental para o estabelecimento de práticas de melhoria da fertilidade do solo, que visem à maior eficiência dos sistemas de produção agrícola e ao uso eficiente dos recursos naturais.

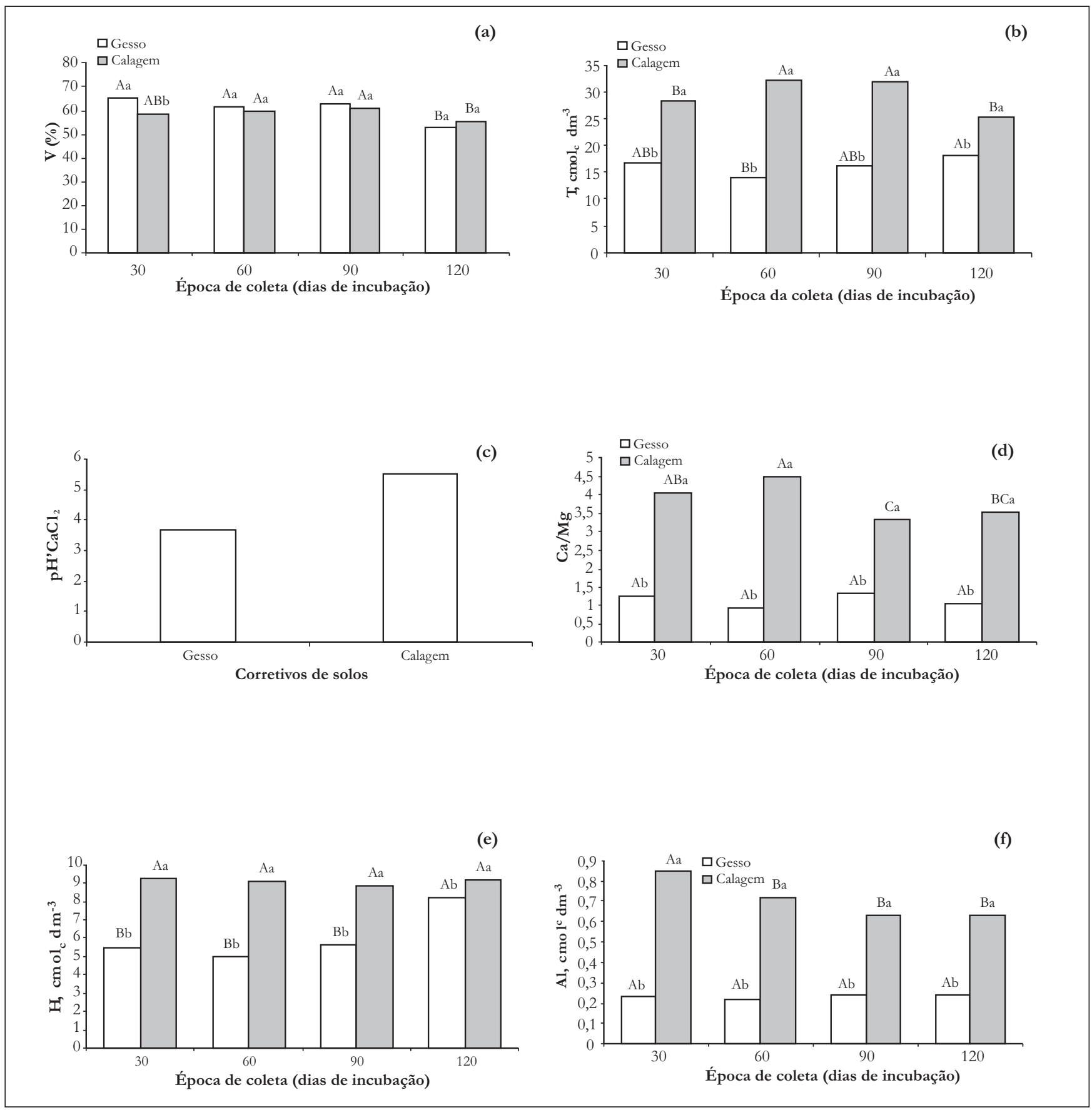

Figura 2 - Influência do período de incubação da gessagem e calagem recomendada sobre a saturação de base - V (a), capacidade de troca catiônica - T (b), $\mathrm{pH}$ (c), relação $\mathrm{Ca} / \mathrm{Mg}(\mathrm{d})$, hidrogênio - $\mathrm{H}^{+}$(e), e Alumínio - $\mathrm{Al}^{+++}$(f)

Nota: Letras maiúscula iguais nas barras não diferem entre si a 5\%, pelo teste de Tukey, entre as épocas de coletas utilizadas; letras minúscula iguais nas barras não diferem entre si a 5\%, pelo teste de Tukey, no mesmo período entre gessagem e calagem. Na Figura 2C não houve interação entre os corretivos e a época de coleta, e os tratamentos não diferenciaram entre si. 
A resposta dos corretivos na disponibilidade dos nutrientes, principalmente da calagem, está diretamente ligada ao tempo após a colocação do corretivo no solo (Figura 3). Na sua maioria, os solos brasileiros são ácidos, destacando-se aqueles sob vegetação de Cerrado. Tais solos são caracterizados por baixas saturações por base, concentrações de cálcio e de magnésio (elementos diretamente envolvidos no desenvolvimento das raízes) e por valores elevados de alumínio trocável e baixa disponibilidade de fósforo do solo. De acordo com Souza et al. (2007), a acidez do solo, quando em excesso, pode ocasionar alterações na química e fertilidade, restringindo o crescimento das plantas. Tais restrições podem ocorrer na camada mais explorada pelas raízes, nos $20 \mathrm{~cm}$ superficiais do solo, reduzindo o crescimento radicular e limitando a absorção de água e nutrientes.

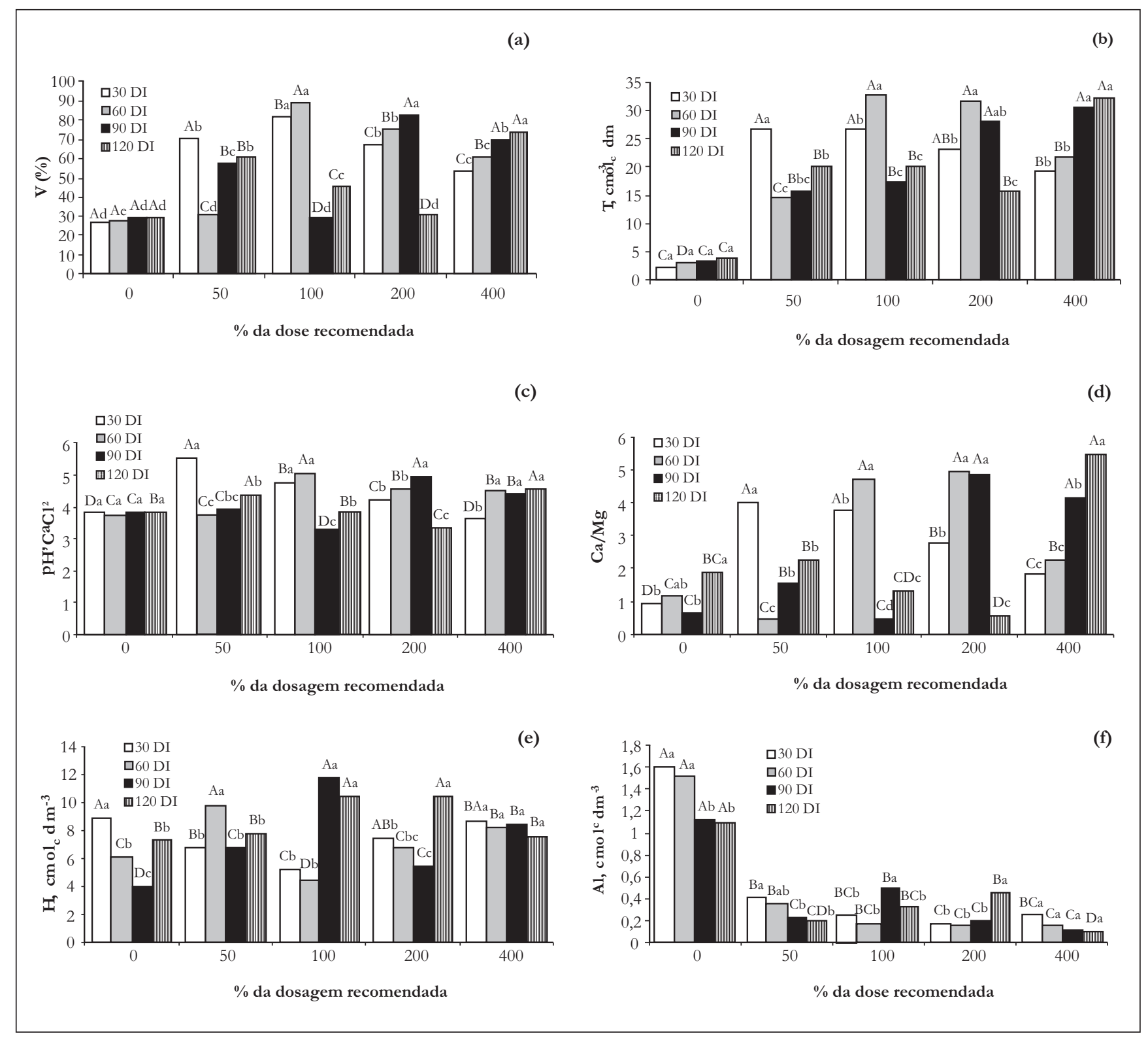

Figura 3 - Influência da interação entre a porcentagem dos corretivos nos diferentes períodos de incubação sobre a saturação de base - V (a), capacidade de troca catiônica - T (b), $\mathrm{pH}$ (c), relação Ca: $\mathrm{Mg}$ (d), hidrogênio - $\mathrm{H}^{+}$(e), e Alumínio - $\mathrm{Al}^{+++}(\mathrm{f})$

Nota: Letras maiúscula iguais nas barras não diferem entre si a 5\%, pelo teste de Tukey, entre as porcentagens de gessagem e calagem recomendada; letras minúscula iguais nas barras não diferem entre si a 5\%, pelo teste de Tukey, na mesma dose de corretivo nos diferentes períodos de incubação. 


\section{Conclusões}

- A gessagem e a calagem influenciam nos atributos químicos do solo em função das doses analisadas e do período de incubação;

- De forma geral, a fertilidade dos solos foi melhorada com a aplicação do corretivo (calcário) e do aditivo (gesso).

\section{Agradecimentos}

Os autores agradecem ao CNPq pelas bolsas concedidas, ao Fieto/Senae, à Universidade Federal do Tocantins e à Caltins, pelo apoio, o que tornou este trabalho possível.

\section{Referências}

BLEVINS, R. L.; MURDOCK, L. W.; THOMAS, G. W. Effect of lime application on no-tillage and conventionally tilled corn. Agronomy Journal, v. 70, n. 1, p. 322-326, 1978.

CAIRES, E. F.; BANZATTO, D. A.; FONSECA, A. F. Calagem na superfície em sistema plantio direto. Revista Brasileira de Ciência do Solo, v. 24, n. 1, p. 161-169, 2000.

CAIRES, E. F.; BLUM, J.; BARTH, G. Alterações químicas do solo e resposta da soja ao calcário e gesso aplicados na implantação do sistema plantio direto. Revista Brasileira de Ciência do Solo, v. 27, n. 2, p. 275-286, 2003.

CAMERON, R. S.; RITCHIE, G. S. P.; ROBSON, A. D. Relative toxicities of inorganic aluminum complexes to barley. Soil Science Society of America Journal, v. 50, p. 1231-1236, 1986.

CHAN, K. Y.; HEENAN, D. P. Lime-induced loss of soil organic carbon and effect on aggregate stability. Soil Science Society of America Journal, v. 63, p. 1841-1844, 1999.

CARVALHO, M. C. S.; RAIJ, B. van. Calcium sulphate, phosphogypsum and calcium carbonate in the amelioration of acid subsoils for root growth. Plant Soil, v. 192, p. 37-48, 1997.

CHAVES, J. C. D.; PAVAN, M. A.; IGUE, K. Resposta do cafeeiro à calagem. Pesquisa Agropecuária Brasileiora, v. 19, n. 5, p. 573-582, 1984.

CORSI, M.; NUSSIO, G. Manejo do capim-elefante: correção do solo. In: SIMPÓSIO SOBRE MANEJO DE PASTAGEM, 10., 1992, Piracicaba. Anais... Piracicaba: FEALQ, 1992. p. 87-117.

EMPRESA BRASILEIRA DE PESQUISA AGROPECUÁRIA - EMBRAPA. Manual de métodos de análise de solo. 2. ed. Rio de Janeiro: Embrapa-CNPS, 1997.

ERNANI, P. R. et al. Decréscimo da retenção de fósforo no solo pelo aumento do pH. Revista Brasileira de Ciência do Solo, n. 20, p. 159-162, 1996.

ERNANI, P. R.; NASCIMENTO, J. A. L.; OLIVEIRA, L. C. Increase of grain and green matter of corn by liming. Revista Brasileira de Ciência do Solo, v. 22, n. 2, p. 275-280, 1998.

GOMES, F. T. Nodulação, fixação de nitrogênio e produção de matéria seca de alfafa em resposta a doses de calcário, com diferentes relações cálcio:magnésio. Ciência Rural, v. 32, n. 6, p. 925-930, 2002.

GONZÁLES-ERICO, E. et al. Effect of depth of lime incorporation on the growth of corn on an Oxisol of Central Brazil. Soil Science Society of America Journal, v. 43, p. 1155-1158, 1979. 
HAINBERG, I. et al. Use of gypsum on soils: a review. Advanced Soil Science, v. 9, n. 1, p. 1-111, 1989.

MASSOT, N.; POSCHENRIEDER, C.; BARCELÓ, J. Differential response of three bean (Phaseolus vulgaris L.) cultivars to aluminum. Acta Botanica Neerlandica, v. 41, p. 293-298, 1992.

MOSCHLER, W. W. et al. Comparative lime effects on continuous no-tillage and conventionally tilled corn. Agronomy Journal, v. 65, p. 781-783, 1973.

OATES, K. M.; CALDWELL, A. G. Use of by-product gypsum to alleviate soil acidity. Soil Science Society of America Journal, v. 49, p. 915-918, 1985.

OLIVEIRA, E. L.; PARRA, M. S.; COSTA, A. Resposta da cultura do milho, em um Latossolo VermelhoEscuro álico, à calagem. Revista Brasileira de Ciência do Solo, v. 21, n. 1, p. 65-70, 1997.

OLIVEIRA, E. L.; PAVAN, M. A. Control of soil acidity in no-tillage system for soybean production. Soil and Tillage Research, v. 38, n. 1, p. 47-57, 1996.

PAVAN, M. A.; BINGHAM, F. T.; PRATT, P. F. Redistribution of exchangeable calcium, magnesium and aluminum following lime and gypsum applications to a Brazilian Oxisol. Soil Science Society of America Journal, v. 48, n. 1, p. 33-38, 1984.

QUAGGIO, J. A.; VAN RAIJ, B.; GALO, P. B. Respostas da soja à aplicação de calcário e gesso e lixiviação de íons no perfil do solo. Pesquisa Agropecuária Brasileira, v. 28, n. 3, p. 375-383, 1993.

RITCHEY, K. D. et al. Calcium leaching to increase rooting depth in a Brazilian Savannah Oxisol. Agronomy Journal, v. 72, n. 1, p. 40-44, 1980.

SAS. User guide: statistics. 5th ed. SAS Institute, Cary, NC. 1985. 483 p.

SILVA, A. A. et al. Efeitos de Relações $\mathrm{CaSO}_{4} / \mathrm{CaCO}_{3}$ na mobilidade de nutrientes no solo e no crescimento do algodoeiro. Revista Brasileira de Ciência do Solo, v. 22, p. 451-457, 1998.

SILVA, N. M. et al. Efeitos do calcário e do gesso nas características químicas do solo e na cultura do algodão. Bragantia, v. 56, n. 2, p. 389-401, 1997.

SOUZA, D. M. G.; MIRANDA, L. N.; OLIVEIRA, S. A. Acidez do solo e sua correção. In: NOVAIS R. F. et al. Fertilidade do solo. Viçosa: Sociedade Brasileira de Ciência do Solo, 2007. p. 205-274.

SUMMER, M. E. et al. Amelioration of an acid soil profile through deep liming and surface application of gypsum. Soil Science Society of America Journal, v. 50, p. 1254-1258, 1986.

Recebido: 14/04/2009

Received: 04/14/2009

Aprovado: 22/12/2009

Approved: 12/22/2009 